$\$$ Research Square

\title{
Are Healthy Habits Associated With Reduced Mental Health Problems?
}

Patricia Moreno-Mencia ( $\square$ patricia.moreno@unican.es )

Universidad de Cantabria https://orcid.org/0000-0002-8210-4932

\section{David Cantarero-Prieto}

Universidad de Cantabria

Research

Keywords: Quality of life, Mental Health, Discrete Choice Regression, Multilevel Model

Posted Date: December 11th, 2020

DOI: https://doi.org/10.21203/rs.3.rs-117457/v1

License: (9) This work is licensed under a Creative Commons Attribution 4.0 International License. Read Full License 


\title{
Are healthy habits associated with reduced mental health problems?
}

\author{
Patricia Moreno-Mencia* \\ Group of Health Economics and Health Services Management \\ Department of Economics, University of Cantabria- IDIVAL \\ E39005 Santander, Spain. email: patricia.moreno@unican.es \\ David Cantarero-Prieto \\ Group of Health Economics and Health Services Management \\ Department of Economics, University of Cantabria- IDIVAL \\ E39005 Santander, Spain
}

November 23, 2020

\begin{abstract}
Background

Mental illness is an increasing problem in developed countries and affect a large number of the Spanish population. Moreover, it contributes to early retirement and also some working conditions, such as the stress level or the satisfaction with the job, are associated with an the risk of depressive and anxiety symptoms. The purpose of this article is to investigate the Spanish regional differences in the effect that some life conditions, such as obesity, doing exercise regularly, having a good diet, not smoking or not drinking alcohol has on mental health problems.
\end{abstract}

\section{Methods}

We use data from the Spanish National Health Survey of 2017 in order to estimate a multilevel logit model with the objective to calculate the effects of life conditions factors on mental health outcomes. The main objective is to provide a comparable framework for the Spanish population with different characteristics though multilevel analysis.

\section{Results}

People has in average $10.6 \%$ chances of having depression across all regions. Similarly we can show that in average, the probability of having anxiety problems is a $9.4 \%$ and is a $2.2 \%$ in case of other mental illnesses across the Spanish Regions. Men have less probability of having mental health problems, the same as married people, those with higher level of studies and the ones which are satisfied at work. Moreover, having healthy habits reduce the probability of suffering any mental disorder. On the other hand, older people and obese have more probability of developing a mental illness.

\section{Conclusions}

Mental disorders are a growing public health problem in developed countries. So that, Governments has

${ }^{*}$ corresponding author 
taken measures to deal with the problem such as the prevention. In order to prevent the mental problems they have to concentrate efforts in stress reduction, measures to decrease alcohol and tobacco consumption, to incentive the healthy life avoiding obesity problems, etc.

keywords:Quality of life; Mental Health; Discrete Choice Regression; Multilevel Model

\section{Introduction}

It is known that a large number of factors may contribute to increase the risk for mental disorders such as the genetics, the life experiences, the abuse of drugs and alcohol or having other chronic illness. According to the World Organization of the Health (WHO (2017)) over 2.4 million of people suffer from depression in Spain, that is the $5.2 \%$ of Spanish population. At a global level, over 300 million people are calculated to have depression, a $4.4 \%$ of the world's population. Moreover, the proportions of population with anxiety disorders around the world represented in 2015 the $3.6 \%$ of the population and the $4.1 \%$ in the case of Spain.

According to the World Health Organization (WHO) the mental health is defined as: "a state of well-being in which every individual realizes his or her own potential, can cope with the normal stresses of life, can work productively and fruitfully, and is able to make a contribution to her or his community". Additionally, it is necessary to highlight that the absence of mental disorder does not mean the presence of good mental health. There exist many types of mental disorders such as anxiety, depression, eating disorders, personality disorders...etc. Basically, we are going to assume three main groups: Depression is the feeling of sadness or the loss of interest or pleasure in life. Anxiety, that is the feeling of worry, nervousness or danger. The most common symptoms for anxiety are palpitations, trembling, sweating and accelerated heart rhythm. And finally, Other mental disorders such as eating disorders, schizophrenia, other personality disorders and other mental problems in general.

\section{Background}

Reviewing previous literature we can divide the research in three main groups. A first source of studies have examined the impact of mental disorders in the labor supply. There are several studies linking depression with labor market outcomes. The labor supply is usually associated with health outcomes (Currie (2009)), and in that sense we think there is a negative relation; worse health implies less working hours. Ettner (1996) which used parental history of mental disorders as instrument for own mental disorder. Alexandre and French (2001) used variables associated with religion as instrument for the mental disorder and they showed that depression implied a reduction in the probability of being employed by about a 19\%. Chatterji et al. (2008), related this mental disorder with a reduction in labor participation (about 9-11 points) and pointed out that having a mental illness such as depression can suppose for the person a costly problem. Thus, there are mainly three aspects that relate depression with employment according to Chatterji et al.; Firstly the lack of motivation, secondly the discrimination because of the employer prejudice and finally the employer is unwillingness to incur in extra cost due to this illness. Azagba and Sharaf (2011) examined the effect of job stress on two key health risk-behaviors: smoking and alcohol consumption, using data from the Canadian National Population Health 


\section{Survey.}

A second source of studies have analyzed the relationship between socio-economic characteristics and mental health problems, Reiss (2013). Usually, health problems have been related with some relevant factors such as the income, see Adeline and Delattre (2017) for example. Moreover, depression is an often mental illness that has been shown to be strongly related with some important life outcomes, such as educational or labor market outcomes (Ettner (1996)). The literature review also suggests that some of the depressive symptoms are different in function of the individual characteristics such as the age, the gender or the kind of illnesses. In this sense, McNeil and Harsany (1989) showed that old people tend to manifest less the emotional symptoms to the doctor than the youngest. Maes (2002) obtained that older people had greater relevance of certain depressive symptoms such as weight problems, lack of reactivity, depressed mood, loss of interest, insomnia, allergies , anxiety, loss of self-esteem, psychotic symptoms and psychomotor retardation. These results coincide with the obtained by Stage et al. (2001) or Sharp and Lipsky (2002) among others. Several authors believe that depression is more related to the existence of other diseases; Franco et al. (2003) concluded that the symptoms that differentiate depression between elder and young adult are those relating to the deadening or future loss.

According to a study published in the British Journal of Psychiatry (King et al. (2008)), the Spanish women are the Europeans who most often suffer from depression and anxiety. The study was conducted with a sample of 7,000 primary care patients in six European countries: Spain , UK, Portugal , Slovenia , Estonia and the Netherlands. Duque-González (2009) estimated that mental illnesses are the second leading cause of permanent and temporary sick leave at work, besides being the fourth leading cause of informal care (provided by persons who are not professional as such but mostly family) with data from 2002, the total cost of mental illness in Spain is estimated in about 7.019 million euros, being the direct medical costs the $39.6 \%$ about the $7.3 \%$ of the total public health expenditure in that year. Moreover, the depression is one of the most common causes of health care in primary attention in Europe (Ivbijaro et al. (2008)) and it is associated with the rate of chronic disability in the individuals. In order to contextualize our objective, part of the most important socioeconomic factors explaining mental health disorders are the referent to lifestyle conditions. This issue is less explored, for example focusing on life conditions, Loewen et al. (2019) concluded that mental disorders during the adolescence was associated with lifestyle factors in childhood and thus, was important to emphasize that pediatric recommendations mat reduce mental health problems. Velten et al. (2014) found that better mental health was highly associated with some healthy conditions such as practising sports, moderate alcohol consumption, non smoking and not being underweight or obese. In the same line, Buttery et al. (2014) found a correlation between better mental health and healthy behaviours. Moreover, some attitudes such as smoking, physical inactivity or having a poor diet were related with suffering depression. In the same line, Parletta et al. (2017) found that a Mediterranean-style diet was associated with a reduction in depression among participants.

Finally, other group of researches are focused on regional differences. The historical context of a place, the political, social or economic characteristics and the cultural norms among others shape the conditions in which people live. These conditions have important effects on mental health and the well being of the society. There exists evidence that unemployment is associated with an increased risk of depression and job insecurity, and 
it is associated with mental health problems. In this context, countries with systems more protective against unemployment have less risk of mental health disorders. The same happens comparing high-income and lowincome countries. Then, it is possible to conclude that the environment has an important role on mental health disorders. Unfortunately, usual regression techniques such as ordinary least squares regression assume that observations are independent, then is not possible to consider the importance of the environment. In the concrete case of Spain, several differences between the Autonomous Communities are related with mental health aspects, and thus it is relevant its investigation. Moreover, today, mental health services are responsibility of the Autonomous Communities and although since 2007 some statal and regional strategies started to be implemented (de Sanidad y Consumo (2007)) there still exits a mismatch between population needs and services provided. González et al. (2004) studies the main territorial inequalities in health care supply. Barros et al. (2010) discussed that socioeconomic factors are not the only type of inequities that are relevant to child health. Gender inequities are important and urban/rural inequities are also relevant, particularly as these affect the availability of health care.

To sum up, the main objective here is to examine the existent links between some healthy habits and mental health. The aspects of good lifestyle studied in this research include the consumption of fruits and vegetables daily, non-smoking and drinking moderate alcohol and practising frequent physical activity, among other characteristics. The aspects of mental health studied are (i) depression, (ii) anxiety and (iii) other mental disorders. We also consider that individuals are influenced by its environment, so that it could be necessary to take into account differences between contexts because the assumption of independence of observations does not hold, and then, the ordinary least squares estimates are inconsistent.

The paper is organized as follows. Section 2 deals with methodological issues and it describes the source of data employed in the empirical application. Section 3 describes the main results relative to the effect of the selected factors on mental health. Finally, section 4 presents the conclusions and discuss policy issues related to mental health disorders.

\section{Methods}

Multilevel models have became really useful nowadays for recognising the existence of hierarchical data. There are review articles on multilevel modeling in the social science field that serve as references in these contexts. Raudenbush (1988) collected applications in educational researches and proposed the term hierarchical linear model (HLM). Blalock (1984) reviewed some models for data at multiple levels called "contextual models," before the hierarchical linear model was popularized in the early 90s. In these cases, the residual variance can be partitioned into a between-area component and a within-area component. The region residuals are the so-called 'region effects', which are the unobserved region characteristics affecting population outcomes.

\subsection{Econometric Model}

The most usual methods for estimating these models are based on likelihood approaches. Our three dependent variables are binary indicators; To suffer depression or not, to have anxiety or not and to have other mental problems or not. First of all, let us to introduce the two-level model, $y_{i j}$ denote the observed response of the 
level 1 unit, $i=1, \ldots, n_{j}$ belonging to region $\mathrm{j}, j=1 \ldots . . n$. Thus,

$$
\begin{gathered}
y_{i j}= \begin{cases}1 & \text { for } y_{i j}^{*}>0, \\
0 & \text { otherwise. }\end{cases} \\
y_{i j}^{*}=\beta_{0}+\beta_{1}^{T} x_{1 i j}+\beta_{2}^{T} x_{2 j}+\epsilon_{j}+u_{i j}
\end{gathered}
$$

where $x_{i j}$ is the vector of explanatory variables, we can disaggregate it as: $x_{1 i j}$ being the individual level covariates and $x_{2 j}$ being the region-level covariates for region $j . \epsilon_{j}$ is the unobservable common random effect for all individuals in region $j$. Moreover, $u_{i j}$ is a random disturbance which is assumed to be independently and identically distributed, $u_{i j} \sim N\left(0, \sigma_{u}^{2}\right)$. Then:

$$
\begin{aligned}
E\left[y_{i j} \mid x_{1 i j}, x_{2 j}, \epsilon_{j}, u_{i j}\right] & =\operatorname{logit}\left[P\left[y_{i j}=1 \mid x_{1 i j}, x_{2 j}, \epsilon_{j}\right]\right]= \\
& =\beta_{0}+\beta_{1}^{T} x_{1 i j}+\beta_{2}^{T} x_{2 j}+\epsilon_{j}=\left(\beta_{0}+\epsilon_{0}\right)+\left(\beta_{11} \epsilon_{1 j}\right) x_{1 i j 1}+\left(\beta_{12} \epsilon_{2 j}\right) x_{1 i j 2}+\ldots
\end{aligned}
$$

This corresponds to the most general model but we can star with a more simpler one and then, adding more components step by step. We are going to begin with a null model, that is a model which only includes an intercept and the region effect. Here, the intercept is common for all the Autonomous communities while the random effect $u_{0 j}$ is specific to region $j$. The sample mean is the "fixed" part of the model and the difference between the observation and the mean is the residual or "random" part of the model. Here, the dependence of residuals within a country has been considered, because the constant term may differ across regions. $y_{i j}$ is a binomial variable with mean $\mu_{i j}=\pi_{i j}$.

$$
\begin{aligned}
\operatorname{logit}_{i j}=\ln \left(\frac{\pi_{i j}}{1-\pi_{i j}}\right) & =\beta_{0 j}+u_{i j}, \\
\text { where } \beta_{0 j} & =\gamma_{00}+v_{0 j}
\end{aligned}
$$

Here, $\beta_{0 j}$ can be interpreted as the mean probability of suffering mental disorders, whereas $\gamma_{00}$ is the mean across all individuals and regions. In the first level, $\log \frac{\pi_{i j}}{1-\pi_{i j}}$ represents the outcome for level one unit i nested in level two unit $\mathrm{j}$, and is equal to a level one intercept, $\beta_{0 j}$, and residual or unexplained variance $u_{i j}$. The error term $u_{i j}$ shows how the probability of having a mental disorder deviates from the mean evaluation in the region in which he lives. The level 2 error term, $v_{0 j}$, shows how the mean of probability of having a mental disorder in a concrete region deviates from the grand mean. That equation can also be displayed in its mixed model form, by simply substituting the level 2 equation into the level 1 equation. Predictor variables can also be added to the model at level 1, level 2, or both.

$$
\begin{aligned}
\ln \left(\frac{\pi_{i j}}{1-\pi_{i j}}\right) & =\beta_{0 j}+\beta_{1 j} x_{1 i}+\ldots+\beta_{k j} x_{k i}+u_{i j}, \\
\beta_{0 j} & =\gamma_{00}+\gamma_{01} w_{1 i}+\ldots+\gamma_{0 k} w_{k i}+v_{0 j} \\
\beta_{1 j} & =\gamma_{10}+\gamma_{11} w_{1 i}+\ldots+\gamma_{1 k} w_{k i}+v_{1 j} \\
\beta_{2 j} & =\ldots
\end{aligned}
$$

We have considered a wide range of explanatory variables. At level 1, we have considered the age, the gender, the marital status, the level of studies, the satisfaction at job, the practise of exercise, the diet and the alcohol and tobacco consumption. Level 2 variables, include the proportion of obesity per region, the level of unemployment, the average of age and the rate of people with good health. 


\subsection{Assumptions}

In this model, the errors are not independent across level 1 units (individuals), instead there is dependency among level 1 units nested within each level 2 unit (region) in the terms $v_{0 j}$ and $v_{1 j}$. In addition, the variances of the errors may no longer be homogeneous if $v_{0 j}$ and $v_{1 j}$ take on different values within each level 2 unit (region).

In the level 2 (country-level) models we assume that the parameters $\beta_{0 j}$ and $\beta_{1 j}$ are distributed as multivariate normal with means $\gamma_{00}$ and $\gamma_{10}$, respectively, and variances $\tau_{00}$ and $\tau_{11}$, respectively. Finally, level 1 and level 2 errors are uncorrelated.

\subsection{Data}

The data came from the National Health Survey. The sample was drawn from Spanish population using simple random sampling and was carried out in 2017 by the Statistics Spanish Institute. The final study group consisted of 9,919 individuals distributed in 19 regions (the 17 Spanish Autonomous Communities and the Autonomous Cities of Ceuta and Melilla). This survey is representative at national and Autonomous Community level and collects information about important health indicators and life conditions such as tobacco and alcohol consumption, obesity, mental health, diabetes, or some risk factors among other. The main objective of this survey is to provide information about the health of the Spanish population according to their demographic and socioeconomic characteristics, and by Autonomous Community.

\subsection{Variables}

- The Dependent variables: We consider three; the onset of depression, anxiety or other mental disorders. These variables are self-reported. Individuals were asked with a question: Did you suffer from depression in the last year? and they answered YES or NOT. The same with anxiety or other mental problems.

- The Individual-level covariates chosen for this analysis included age, gender (if male or not), marital status (married versus not), satisfaction at job(satisfied at job versus not), university studies, if the person practices exercises several times per week (yes versus not), if the person eats at least one fruit per day (yes versus not), if the individual smokes (yes versus not), If the person does not drink alcohol (yes versus not).

- The Regional-level covariates are the rate of unemployment that year in each Region, the proportion of population declaring good health per region and the obesity rate in each region (A subject has obesity if its BMI is higher than 30).

The choice of these variables follow the evidences established in previous literature researches. Usually to analyse healthy habits it is necessary to inspect three factors: The diet, the physical activity and the consume of dangerous substances such as alcohol or tobacco. In the survey, people had to answer the frequency they drunk alcohol in last year or if they never drunk alcohol, if they smoke, if they usually eat at least one fruit per day and if they practised physical activity several times per week. The choice of these variables is in line to the explained above and also related with previous research. For example, Jacka et al. (2013)examined the 

cultural backgrounds. They found evidence for an association between an unhealthy diet and mental health problems. Muńoz et al. (2008) showed that adherence to the Mediterranean diet was associated with higher scoring for self-perceived mental health. Focusing on physical activity, ? declared that mental health service providers found evidence that physical activity was beneficial for individuals suffering from mental disorders. Finally, the adverse effects on health related with smoking and alcohol drinking have object of study of several researchers. According to WHO (2011) smoking is the leading preventable cause of disease and premature death in the world. Moreover, tobacco is strongly associated with psychiatric disorders, Minichino et al. (2013) showed that smokers are more likely than non-smokers to suffer mental disorders. Additionally, alcohol abuse has also adverse effects on mental and physical health, Testino (2008). Makela et al. (2014) declared that alcohol problems are associated with poor mental health. In this line, they found a lack of life satisfaction associated with individuals which drunk more alcohol.

Moreover, mental health is usually correlated with the stress level and the optimism, so that we have included as control if the individual is satisfied at job. Additionally we have included some usual variables in explaining health problems such as the age, the gender or the marital status. Finally, the regional level variables have been chosen for accounting for the general feeling of health perceived, the obesity rate and the level of unemployment. We have the hypothesis that regions with less unemployment, less obesity rate and higher proportion of people reporting good health can englobe people with less mental problems.

According to Table 1, the $11.3 \%$ of the Spanish population practise exercise several times per week and the $20.4 \%$ declare not to drink alcohol. Moreover, the $66.3 \%$ of the Spanish population eat at least one fruit per day. Nevertheless, the $16.9 \%$ is obese, the $21.2 \%$ smoke and the $1.54 \%$ drink alcohol 5 or 6 times per week. The $28.5 \%$ of the Spaniards are satisfied with their jobs, but the $10 \%$ of our population declared to be very stressed. Finally, on average, the $66.4 \%$ reported to have good or really good health although the $69.2 \%$ of the whole population had any chronic illness. 
Table 1: Main Statistics

\begin{tabular}{|c|c|c|c|}
\hline Variable & Definition & Mean & S.D. \\
\hline \multicolumn{4}{|l|}{ Individual Characteristics } \\
\hline Age & Age in years & 53.4 & 18.9 \\
\hline Men & Takes value 1 if it is a men & 0.459 & 0.498 \\
\hline Single & Takes value 1 if it is single & 0.255 & 0.436 \\
\hline Married & Takes value 1 if it is married & 0.540 & 0.498 \\
\hline Widow & Takes value 1 if it is widow & 0.129 & 0.335 \\
\hline \multicolumn{4}{|l|}{ Level of Studies } \\
\hline Without studies & Takes value 1 if the person had no studies & 0.119 & 0.324 \\
\hline Elementary Studies & Takes value 1 if the person has elementary studies & 0.193 & 0.395 \\
\hline Medium Studies & Takes value 1 if the person has medium studies & 0.506 & 0.500 \\
\hline University Studies & Takes value 1 if the person has universitary studies & 0.181 & 0.385 \\
\hline \multicolumn{4}{|l|}{ Labour Factors } \\
\hline Working & Takes value 1 if the person has a job & 0.430 & 0.495 \\
\hline Public Employee & Takes value 1 if the person works in Public Sector & 0.112 & 0.316 \\
\hline Long-term contract & Takes value 1 if the person has a long-term job & 0.531 & 0.499 \\
\hline Short-term contract & Takes value 1 if the person has a short-term job & 0.157 & 0.364 \\
\hline Employee & Takes value 1 if the person is an employee & 0.773 & 0.419 \\
\hline Employer & Takes value 1 if the person is an employer & 0.218 & 0.413 \\
\hline \multicolumn{4}{|l|}{ Health Factors } \\
\hline Good or very good health & Takes value 1 if the person reported to have good health & 0.664 & 0.472 \\
\hline Bad or very bad health & Takes value 1 if the person reported to have bad health & 0.0963 & 0.295 \\
\hline Chronic illness & Takes value 1 if the person has any chronic illness & 0.692 & 0.462 \\
\hline Depression & Takes value 1 if the person has depression & 0.116 & 0.320 \\
\hline Anxiety & Takes value 1 if the person has anxiety problems & 0.0986 & 0.298 \\
\hline Other mental problems & Takes value 1 if the person has other mental disorder & 0.0221 & 0.147 \\
\hline \multicolumn{4}{|l|}{ Life Conditions } \\
\hline Without stress & Takes value 1 if the person reported not to have stress & 0.0706 & 0.256 \\
\hline Very stressed & Takes value 1 if the person reported to have a lot of stress & 0.100 & 0.300 \\
\hline Non satisfactory job & Takes value 1 if the person has a non satisfactory job & 0.0184 & 0.135 \\
\hline Satisfactory job & Takes value 1 if the person has a satisfactory job & 0.285 & 0.452 \\
\hline Exercises several times per week & Takes value 1 if the person practices exercise several days per week & 0.113 & 0.317 \\
\hline One or more than one fruit per day & Takes value 1 if the person eats at least one fruit per day & 0.663 & 0.473 \\
\hline Smoking & Takes value 1 if the person smokes & 0.212 & 0.409 \\
\hline obese & Takes value 1 if the person is obese & 0.169 & 0.375 \\
\hline
\end{tabular}

Source: Own Elaboration from National Health Survey of 2017

As we can observe, in Spain, about the $11.6 \%$ of the population declare to have depression, the $9.8 \%$ anxiety and the $2.21 \%$ other mental problems according to the information collected by the National Health Survey of 2017. 


\section{Findings}

This section comprises the main result of the study. With the objective of have a first impression, we can estimate the effect of obesity on the probability of developing a mental illness. As we can observe in Table 2, is 1.68

Table 2: Logit model estimation

\begin{tabular}{|l|l|l|l|l|l|l|l|l|l|}
\hline & \multicolumn{4}{|c|}{ Depression } & \multicolumn{3}{c|}{ Other Mental Problems } \\
\hline & Odds Ratio & Std.Err & P-value & Odds Ratio & Std.Err & P-value & Odds Ratio & Std.Err & P-value \\
\hline Constant & 0.117 & 0.002 & 0.000 & 0.101 & 0.002 & 0.000 & 0.021 & 0.001 & 0.021 \\
\hline Obese & 1.683 & 0.082 & 0.000 & 1.490 & 0.079 & 0.000 & 1.291 & 0.142 & 0.000 \\
\hline
\end{tabular}

Source: Own Elaboration from National Health Survey of 2017

times more probable that an obese individual can have depression than a non obese one. Similarly the probability of having anxiety problems is 1.49 more probable for obese people and 1.29 in case of other mental problems.

The explained models have been estimated by maximum likelihood estimation using adaptative quadrature with 12 integration points. The results of the null model if multilevel analysis provide us a total of 23,089 observations in 19 groups, with a mean of 255 people in each group.

Table 3: Null Model Estimation.

\begin{tabular}{|l|l|l|l|l|l|l|l|l|l|}
\hline & \multicolumn{3}{|c|}{ Depression } & \multicolumn{3}{c|}{ Anxiety } & \multicolumn{3}{c|}{ Other Mental Problems } \\
\hline & Coef. & Std.Err & P-value & Coef. & Std.Err & P-value & Coef. & Std.Err & P-value \\
\hline Constant & -2.128 & 0.090 & 0.000 & -2.269 & 0.081 & 0.000 & -3.813 & 0.058 & 0.000 \\
\hline Region sd (constant) & 0.377 & 0.071 & & 0.332 & 0.060 & & 0.122 & 0.068 & \\
\hline
\end{tabular}

Source: Own Elaboration from National Health Survey of 2017

According to Table 3 , in the null model, the estimated intercept was 2.13 , while the estimated variance of the random effects was 0.116. Thus, at an average region (i.e., a region whose random effect was equal to zero on the logit scale), the probability of having depression was $\frac{\exp (-2.128)}{1+\exp (-2.128)}=0.106$. People has on average $10.6 \%$ chances of having depression across all regions. Similarly we can show that on average, the probability of having anxiety problems is a $9.4 \%$ and is a $2.2 \%$ in case of other mental illnesses across the Spanish Regions. The likelihood ratio statistic for testing if the variance is zero can be carry out. Here, the test statistic is 184.56 , with a corresponding p-value smaller than 0.05 so there exists evidence that the between region variance is non zero. Thus, for $95 \%$ of regions, the region-specific probability of having depression would lie in the interval $(-2.30,-1.95)$. This was computed by taking the inverse logit transformation of the interval $-2.128 \pm 1.96 * 0.090$. Similarly, we can obtain the confidence intervals for anxiety and other mental disorders. The variance of the random effect is the square of the standard deviation, so that is estimated to be 0.116 in the first regression. 
Table 4: Random intercept model estimation

\begin{tabular}{|c|c|c|c|c|c|c|}
\hline & \multicolumn{2}{|c|}{ Depression } & \multicolumn{2}{|c|}{ Anxiey } & \multicolumn{2}{|c|}{ Others Mental } \\
\hline & $\begin{array}{l}\text { Coef. } \\
\text { (Std. Err) }\end{array}$ & Odds Ratio & $\begin{array}{l}\text { Coef. } \\
\text { (Std. Err) }\end{array}$ & Odds Ratio & $\begin{array}{l}\text { Coef. } \\
\text { (Std. Err) }\end{array}$ & Odds Ratio \\
\hline Constant & $\begin{array}{l}0.693 \\
(1.333) \\
\end{array}$ & $\begin{array}{l}0.499 \\
(0.665)\end{array}$ & $\begin{array}{l}-1.060 \\
(1.372) \\
\end{array}$ & $\begin{array}{l}0.346 \\
(0.475)\end{array}$ & $\begin{array}{l}-1.783 \\
(2.914)\end{array}$ & $\begin{array}{l}0.167 \\
(0.489)\end{array}$ \\
\hline Male & $\begin{array}{l}-1.120^{* * *} \\
(0.100)\end{array}$ & $\begin{array}{l}0.326 \\
(0.032)\end{array}$ & $\begin{array}{l}-0.928^{* * *} \\
(0.089)\end{array}$ & $\begin{array}{l}0.395 \\
(0.035)\end{array}$ & $\begin{array}{c}-0.456 \\
(0.277)\end{array}$ & $\begin{array}{l}0.633 \\
(0.176)\end{array}$ \\
\hline Age & $\begin{array}{l}0.082^{* * *} \\
(0.033)\end{array}$ & $\begin{array}{l}1.086 \\
(0.036)\end{array}$ & $\begin{array}{l}0.062^{* * *} \\
(0.029)\end{array}$ & $\begin{array}{l}1.044 \\
(0.034)\end{array}$ & $\begin{array}{l}-0.003 \\
(0.026)\end{array}$ & $\begin{array}{l}0.997 \\
(0.086)\end{array}$ \\
\hline Age2 & $\begin{array}{l}-0.0004 \\
(0.0003)\end{array}$ & $\begin{array}{l}0.999 \\
(0.0003)\end{array}$ & $\begin{array}{l}-0.0004 \\
(0.0003)\end{array}$ & $\begin{array}{l}0.999 \\
(0.003)\end{array}$ & $\begin{array}{l}-0.0002 \\
(0.001) \\
\end{array}$ & $\begin{array}{l}0.997 \\
(0.001)\end{array}$ \\
\hline Married & $\begin{array}{l}-0.648^{* * *} \\
(0.092)\end{array}$ & $\begin{array}{l}0.523 \\
(0.048) \\
\end{array}$ & $\begin{array}{l}-0.429 * * * \\
(0.084)\end{array}$ & $\begin{array}{l}0.650 \\
(0.055)\end{array}$ & $\begin{array}{l}-0.937^{* * *} \\
(0.296) \\
\end{array}$ & $\begin{array}{l}0.391 \\
(0.116)\end{array}$ \\
\hline University & $\begin{array}{l}-0.549^{* * *} \\
(0.115)\end{array}$ & $\begin{array}{l}0.577 \\
(0.066)\end{array}$ & $\begin{array}{l}-0.301^{* * *} \\
(0.098)\end{array}$ & $\begin{array}{l}0.739 \\
(0.073)\end{array}$ & $\begin{array}{l}-0.892^{* *} \\
(0.414)\end{array}$ & $\begin{array}{l}0.733 \\
(0.287)\end{array}$ \\
\hline Satisfaction at job & $\begin{array}{l}-0.289^{* * *} \\
(0.107)\end{array}$ & $\begin{array}{l}0.748 \\
(0.080) \\
\end{array}$ & $\begin{array}{l}-0.089 \\
(0.093)\end{array}$ & $\begin{array}{l}0.914 \\
(0.085)\end{array}$ & $\begin{array}{l}-0.309 \\
(0.329)\end{array}$ & $\begin{array}{l}0.733 \\
(0.241) \\
\end{array}$ \\
\hline Exercices several times per week & $\begin{array}{l}-0.555^{* * *} \\
(0.180)\end{array}$ & $\begin{array}{l}0.574 \\
(0.103) \\
\end{array}$ & $\begin{array}{l}-0.417^{* * *} \\
(0.153) \\
\end{array}$ & $\begin{array}{l}0.658^{* * *} \\
(0.100)\end{array}$ & $\begin{array}{l}-0.765 \\
(0.604) \\
\end{array}$ & $\begin{array}{l}0.464 \\
(0.280) \\
\end{array}$ \\
\hline One or more fruits per day & $\begin{array}{l}-0.247^{* * *} \\
(0.099)\end{array}$ & $\begin{array}{l}0.781 \\
(0.078)\end{array}$ & $\begin{array}{l}-0.237^{* * *} \\
(0.089)\end{array}$ & $\begin{array}{l}0.789 \\
(0.070)\end{array}$ & $\begin{array}{l}-0.769 * * * \\
(0.290)\end{array}$ & $\begin{array}{l}0.463 \\
(0.134)\end{array}$ \\
\hline Smoking & $\begin{array}{l}0.198 * * \\
(0.099)\end{array}$ & $\begin{array}{l}1.218 \\
(0.122)\end{array}$ & $\begin{array}{l}0.197^{* * *} \\
(0.091)\end{array}$ & $\begin{array}{l}1.218 \\
(0.111)\end{array}$ & $\begin{array}{l}0.356^{* *} \\
(0.283)\end{array}$ & $\begin{array}{l}1.428 \\
(0.404)\end{array}$ \\
\hline Obese & $\begin{array}{l}0.266^{* * *} \\
(0.122)\end{array}$ & $\begin{array}{l}1.305 \\
(0.160) \\
\end{array}$ & $\begin{array}{l}0.203^{* *} \\
(0.115) \\
\end{array}$ & $\begin{array}{l}1.225 \\
(0.141) \\
\end{array}$ & $\begin{array}{l}0.873^{* * *} \\
(0.319)\end{array}$ & $\begin{array}{l}2.314 \\
(0.765) \\
\end{array}$ \\
\hline Regional Unemployment & $\begin{array}{l}0.930 \\
(1.854)\end{array}$ & $\begin{array}{l}2.534 \\
(4.699) \\
\end{array}$ & $\begin{array}{l}-1.858 \\
(2.004)\end{array}$ & $\begin{array}{l}0.155 \\
(0.312)\end{array}$ & $\begin{array}{l}-10.404^{* * *} \\
(4.646)\end{array}$ & $\begin{array}{c}0.00003 \\
(0.0001)\end{array}$ \\
\hline Regional rate of good health & $\begin{array}{l}-6.008^{* * *} \\
(1.655)\end{array}$ & $\begin{array}{l}0.002 \\
(0.004)\end{array}$ & $\begin{array}{l}-3.747^{* * *} \\
(1.826)\end{array}$ & $\begin{array}{l}0.0235 \\
(0.043)\end{array}$ & $\begin{array}{l}-1.081 \\
(2.914)\end{array}$ & $\begin{array}{l}0.339 \\
(1.165)\end{array}$ \\
\hline Region: var(_cons) & \multicolumn{2}{|c|}{$\begin{array}{c}0.039 * * * \\
(0.031)\end{array}$} & \multicolumn{2}{|c|}{$\begin{array}{c}0.065^{* * *} \\
(0.035)\end{array}$} & \multicolumn{2}{|c|}{$\begin{array}{c}0.000 * * * \\
(0.000)\end{array}$} \\
\hline
\end{tabular}

Source: Own Elaboration from National Health Survey of 2017

The upper section of the Table 4 shows the fixed-effects part of the model while the lower row give us 
an estimated variance of the random intercepts. The likelihood-ratio tests reported in the three regressions confirm that this model (random-intercept-model) is better than the a linear regression model with only fixed effects $(p-$ values $=0.000<0.05)$. The majority of the chosen predictors have significant effects. Men have less probability of having mental health problems, the same as married people, those with higher level of studies and the ones which are satisfied at work. Moreover, having healthy habits reduce the probability of suffering any mental disorder (doing exercises regularly, eating at least one fruit per day and not smoking). On the other hand, older people and someone with obesity have more probability of developing a mental illness. Although the regional variable of rate of unemployment is mostly not significant we have decided to include it because it controls for an important possible disparity across Regions. Moreover, the square of the age is in general not significant, we have tried with or without this variable, but the results remain almost similar.

Despite we have calculate also a Random Slope Model, we have conducted a likelihood ratio test of null hypothesis of no differences in fit between the more complex model (Random slope model) and the simpler one (Random intercept model) and we obtain a p-value of 0.906 (Do not to reject the null hypothesis that the regional variances are both zero), so in this case a random intercept model would be more appropriate than a random slope model. As the same happens with the other two outcomes (anxiety and other mental illnesses) we have discarded the random slope model.

\section{Discussion}

This article examines the impact of some life conditions on individuals mental disorders using multilevel models with data from the Spanish Autonomous Communities. We found that after accounting for individual-level age, marital status, level of studies, satisfaction at job and life conditions (eating fruits, not drinking alcohol or smoking) the regions with higher proportion of people with obesity was associated with higher odds in mental health problems. In the null model, without the inclusion of individual or contextual independent variables, the variance attributable to the place of residence was not statistically significant for any of the dependent variables studied. Contrary to our expectation, living in a region with higher unemployment rate was not significantly associated with suffering depression or anxiety and negatively related with other mental disorders. The obtained results indicate that the environmental characteristics of the region of living are significant. Moreover, almost all the individual factors chosen are significant for explaining the probability of suffering any mental disorder.

Furthermore, these results have implications for planning the distribution of health care services in the Spanish regions. Living in regions with best level of health perceived significantly affect for reducing the probability of having mental health problems. This may be the result of the planning strategies for improving regional health care services and attention. In the individual level, being a man, married, with university studies, satisfied at job, with usual physical activity, not smokers nor alcohol drinkers and those eating at least a fruit per day have less probability to have any mental disorder.

This study has some potential limitations. Due to the cross-sectional nature of the results presented, it was 
not possible to establish a temporal relationship between the onset of mental illnesses and healthy life factors. Moreover, we cannot exclude the possibility of reverse causality, joining individuals with mental disorder in areas with less healthy habits. Additionally, the variables of interest are self-reported, that means that individuals are asked if they have a mental disorder or not. Despite theses limitations, that do not seem to be very serious, this study provides important information to analyse mental health disorders and the empirical results give us valid conclusions about the impact of healthy habits on the probability of suffering a mental disorder. Knowing the determinants of poor mental health is necessary to plan adequate strategies to reduce the risk and health inequality.

\section{Conclusions}

Mental disorders are a growing public health problem in developed countries. Thus, given the public health importance of the common mental health disorders it is something surprising the existing lack of researches investigating the effect of healthy habits at both, individual and region-level on mental disorders. In this study, we have found that life conditions affect significantly the risk of having mental problems. So that, Governments has taken measures to deal with the problem such as the prevention. We conclude that public health policies dedicated to improve lifestyle are convenient to have better mental health in our society. Is is important to take care of our mind and not only of our body to reduce risk of suffering any mental disorder. In order to prevent these mental problems policy makers have to concentrate efforts in stress reduction, measures to decrease alcohol and tobacco consumption, to incentive the healthy life avoiding obesity problems, etc. Once the problem exist, authorities can manage the problem creating psychiatric hospitals and trying to integrate the mental illness as something common in daily life. That mean, to help the mental ills to integrate in the society avoiding handicaps about mental disorders with more information and help measures. Finally, other potentially direction for future research could be to investigate the effects of healthy life condition on mental health problems across regions but also in a longitudinal setting to take into account the effect of time.

\section{Ethics approval and consent to participate}

Not Applicable

\section{Consent for publication}

Not Applicable

\section{Availability of data and materials}

The datasets analysed during the current study are available in the National Health Survey repository from the Spanish National Statistics Institute. https ://www.ine.es/dyngs/INEbase. No special permissions needed to obtain the data. 


\section{Funding}

Not Applicable.

\section{Author's contributions}

The main objective is to provide a comparable framework for the Spanish population with different characteristics though multilevel analysis. All authors read and approved the final manuscript and they have equal contribution. PMM - Wrote the Background section, performed the part of Methods, interpreted the results, drafted the abstract and tables and revised the manuscript. DCP revised the manuscript, interpreted the obtained results and proposed the discussion and main conclusions.

\section{Acknowledgments}

The authors gratefully acknowledge financial support from the Programa Estatal de Fomento de la Investigacion Cientifica y Técnica y de Innovación /Spanish Ministry of Economy and Innovation. Ref: PID2019$105986 G B-C 22$.

\section{Abbreviations}

Not Applicable

\section{8 word count}

4965 characters.

\section{References}

Adeline, A. and E. Delattre (2017). "Some microeconometric evidence on the relationship between health and income". Health Economics Review 7, 1-18.

Alexandre, P. and M. French (2001). "Labor supply of poor residents in metropolitan miami, florida. the role of depression and the co-morbid effects of substance abuse". Journal of Mental Health Policy Economics 4, $161-173$.

Azagba, S. and M. Sharaf (2011). "The effect of job stress on smoking and alcohol consumption". Health Economics Review 1, 1-15. 
Barros, F., C. Victora, R. Scherpbier, and D. Gwatkin (2010). "Health and nutrition of children: equity and social determinants". Equity, social determinants and public health programmes, 49.

Blalock, H. (1984). "Contextual-effects models: Theoretical and methodological issues". Annual Review of Sociology 10, 353-372.

Buttery, A., G. Mensink, and M. Busch (2014). "Healthy behaviours and mental health: finding from the german health update (geda)". European Journal of Public Health 25, 219-225.

Currie, J. (2009). "Healthy, wealthy, and wise: Socioeconomic status, poor health in childhood, and human capital development". Journal of Economic Literature, American Economic Association 47(1), 87-122.

de Sanidad y Consumo, M. (2007). "Estrategia de salud mental. una aproximacion para su conocimiento y desarrollo". Madrid: FEAFES Retrieved from: htpps//consaludmental.org/.

Duque-González, B. (2009). "The socioeconomic costs of mental illness in spain.". European Journal of Health Economics 10(4), 361-369.

Ettner, S. (1996). "The opportunity costs of elder care". Journal of Human Resources 31, 189-205.

Franco, M., A. Sanmartin, J. Guija, and E. Giles (2003). "Difficulties in the evaluation of affective disorders in eldery people". Revista de Psicogeriatría 3(1), 12-16.

González, B., R. Urbanos, and P. Ortega (2004). "Oferta publica y privada de servicios sanitarios por comunidades autonomas". Gaceta sanitaria 18, 82-89.

Ivbijaro, G., L. Kolkiewicz, C. Lionis, I. Svab, A. Cohen, and N. Sartorius (2008). "Primary care mental health and alma-ata: from evidence to action". Mental Health in family medicine 5, 67-69.

Jacka, F., C. Rothon, S. Taylor, M. Berk, and S. Stansfeld (2013). " diet quality and mental health problems in adolescents from east london: a prospective study". Social Psychiatry and Psychiatric Epidemiology 48(8), $1297-1306$.

King, M., J. Semlyen, S. See-Tai, H. Killaspy, D. Osborn, D. Popelyuk, and I. Nazareth (2008). "A systematic review of mental disorder, suicide, and deliberate self harm in lesbian, gay and bisexual people: a systematic review".

Loewen, O., K. Maximova, J. Ekwaru, F. E., M. Asbridge, A. Ohinmaa, and P. Veugelers (2019). "Lifestyle behavior and mental health in early adolescence". Pediatrics 143, 2018-3307.

Maes, M. (2002). "Effects of age and gender on the classification and phenomenology of unipolar depression". Acta Neuropsychiatrica 14, 29-35.

Makela, P., K. Raitasalo, and K. Wahlbeck (2014). "Mental health and alcohol use: a cross-sectional study of the finnish general population". European Journal of Public Health 25, 225-231.

McNeil, J. and M. Harsany (1989). "An age difference view of depression". Canadian Psychology 30, 608-615. 
Minichino, A., F. Saverio, W. Calo, F. Spagnoli, M. Francesconi, R. Viernanza, R. Chiaie, and M. Biondi (2013). "Smoking behaviour and mental health disorders; mutual influences and implications for therapy". International Journal of Environmental Research and Public Health 10, 4790-4811.

Muńoz, M., M. Fito, J. Marrugat, M. Covas, and H. Schröder (2008). "Adherence to the mediterranean diet is associated with better mental and physical health". British Journal of Nutrition, 1821-1827.

Parletta, N., D. Zarnowiecki, J. Cho, A. Wilson, S. Bogomolova, A. Villani, C. Itsiopoulos, T. Niyonsenga, S. Blunden, B. Meyer, L. Segal, B. Baune, and K. O'Dea (2017). "A mediterranean-style dietary intervention supplemented with fish oil improves diet quality and mental health in people with depression: A randomized controlled trial (helfimed)". Nutritional Neuroscience, 1-14.

Raudenbush, S. (1988). "Educational applications of hierarchical linear models: A review". Journal of Educational Statistics 13, 85-116.

Reiss, F. (2013). "Socioeconomic inequalities and mental health problems in children and adolescents: a systematic review". Social Science and Medicine 90, 24-31.

Sharp, L. and M. Lipsky (2002). "Screening for depression across the lifespan: a review of measures for use in primary care settings". American Family Physician 66(6), 1001-1008.

Stage, K., P. Bech, P. Kragh-Sorensen, N. Nair, and C. Katona (2001). "Differences in symptomatology and diagnostic profile in younger and elderly depressed inpatients.". Journal of Affective Disorders 64(2-3), 239-248.

Testino, G. (2008). "Alcohol diseases in hepato-gastroenterology: a point of view". Hepatogastroenterology 55, $371-377$.

Velten, J., K. Lavallee, S. Scholten, A. Meyer, X. Zhang, S. Schneider, and J. Margraf (2014). "Lifestyle choices and mental health: a representative population survey". BMC psychology 58, 1-11.

WHO (2011). Report on the global tobacco epidemic 2011. warning about the dangers of tobacco. Technical report, World Health Organisation.

WHO (2017). Depression and other common mental disorders. Technical report, World Health Organisation. 